\title{
SURGICAL APPROACH IN A PATIENT WITH INTESTINAL MALROTATION ASSOCIATED WITH ADULT HYPERTROPHIC PYLORIC STENOSIS
}

\author{
Veselin IVANOV ${ }^{1}$, Ventsislav DIMOV ${ }^{\circledR}$, Tsonka LUKANOVA ${ }^{1}$, Ivan POPADIIN ${ }^{1}$, Nikola \\ VLADOV ${ }^{1}$
}

${ }^{1}$ Department of Gastroenterology, Hepatopancreatic Surgery and Transplantology, Military Medical Academy, Sofia, Bulgaria

${ }^{2}$ Department of Anaesthesiology and Intensive Care, Military Medical Academy, Sofia, Bulgaria

Received 19 May 2020, Corrections received 29 June 2020, Accepted 24 July 2020

https://doi.org/10.31688/ABMU.2020.55.3.14

\begin{abstract}
Introduction. Intestinal malrotation and hypertrophic pyloric stenosis (HPS) are both rare diseases, usually diagnosed during infancy. In the medical literature there are only a few reports about infants who suffer from a combination of these diseases. The simultaneous occurrence of both diseases in adult patients is extremely rare. However, in this case, the surgical approach has to be a combination of different techniques, aiming at treating each one of the diseases separately.
\end{abstract}

Case presentation. A 37-years-old female patient who presented for upper gastrointestinal symptoms was diagnosed with adult hypertrophic pyloric stenosis (AHPS), intestinal malrotation and consequent dilated stomach. The diagnosis was based on the history, clinical findings, imaging examinations (X-ray, abdominal computed tomography), and gastroscopy. The surgical approach included division of Ladd's band and Jaboulay pyloroplasty.

Conclusions. The simultaneous occurrence of intestinal malrotation associated with AHPS is an extremely

\section{Résumé}

Approche chirurgicale chez un patient souffrant d'une malrotation intestinale associée à une sténose pylorique hypertrophique de l'adulte

Introduction. La malrotation intestinale et la sténose pylorique hypertrophique (SPH) sont des maladies rares, et toutes les deux sont normalement diagnostiquées, dans la plupart des cas, pendant la petite enfance. On peut trouver dans la littérature un nombre restreint des rapports d'enfants qui présentent une combinaison des signes de ces deux maladies. Leur apparition simultanée chez un[e] patient[e] adulte est extrêmement rare. Si tel est le cas quand même, l'approche chirurgicale devrait donc combiner des techniques différentes qui visent un traitement différentiel de chaque maladie.

Rapport du cas. Une patiente de 37 ans qui s'est présentée pour des symptômes gastro-intestinaux supérieurs, diagnostiquée avec une sténose pylorique hypertrophique adulte (SPHA), une malrotation intestinale, et une dilatation de l'estomac conséquente. 
rare condition. Applying a combined surgical approach may have good postoperative results.

Keywords: intestinal malrotation, adult pyloric stenosis, dilated stomach, Ladd's band, Jaboulay pyloroplasty.

\section{Abbreviations list:}

AHPS - adult hypertrophic pyloric stenosis HPS - hypertrophic pyloric stenosis

CT - computed tomography

\section{INTRODUCTION}

Intestinal malrotation is a rare congenital disease, being diagnosed in $0.2 \%$ of all births ${ }^{1}$. Most cases are diagnosed in the first year of life $(75-85 \%)^{2}$. Other cases are discovered in a later stage of life, as an accidental finding or a symptomatic disease and the rest of the cases remain undiagnosed. Adult intestinal malrotation is a very rare condition; its incidence has been reported to be between 0.0001 and $0.19 \%^{3,4}$. The diagnosis of intestinal malrotation in adults is difficult, because of the lack of specific symptoms and the low frequency in the population. The symptoms in adult patients may present as a chronic condition, with intermittent intestinal obstruction or vague abdominal complaints, for months and years,
Le diagnostic a été mis sur la base de l'anamnèse, des résultats cliniques, des examens d'imagerie (radiographie, tomodensitométrie abdominale) et de la gastroscopie. Lapproche chirurgicale a inclus la division de la bande de Ladd et la pyloroplastie Jaboulay.

Conclusions. Le cas d'une malrotation intestinale associée à SPHA est une maladie extrêmement rare. Lapplication d'une approche chirurgicale combinée a bien démontré de très bons résultats postopératoires.

Mots-clés: malrotation intestinale, sténose pylorique adulte, estomac dilaté, bande de Ladd, pyloroplastie Jaboulay.

or as an acute condition with small bowel obstruction $^{5}$.

Adult hypertrophic pyloric stenosis (AHPS) is also a rare disease. It may be divided into 3 types: idiopathic, concomitant and late stage of infantile hypertrophic pyloric stenosis ${ }^{6,7}$. The symptoms of AHPS and the chronic type of intestinal malrotation overlap to some extent.

In this article, we present a rare clinical case of an adult patient with intestinal malrotation associated with AHPS and its surgical treatment.

\section{Case report}

A 27-years-old woman presented with symptoms of epigastric and back pain, nausea, vomiting,

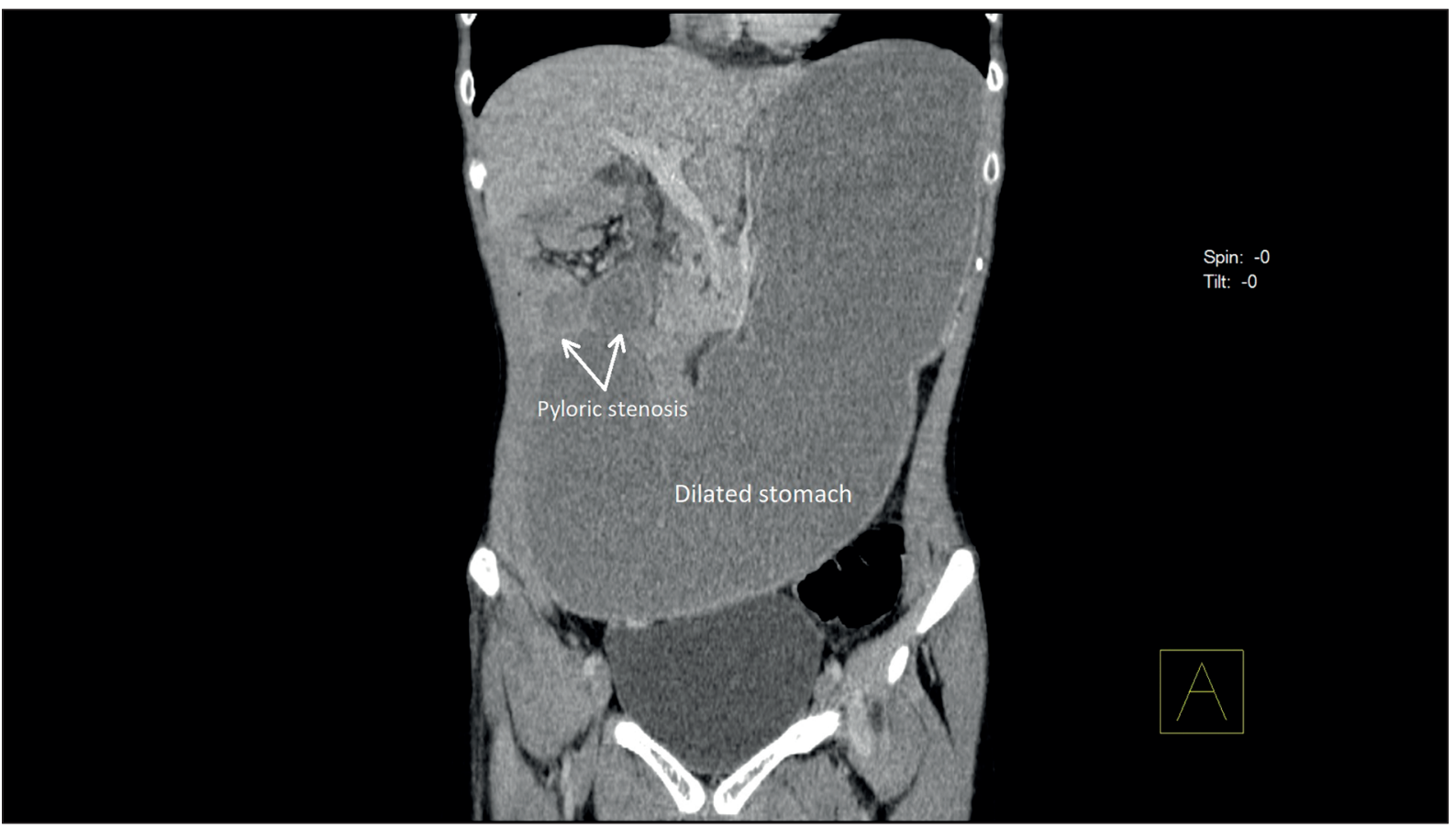

Fig. 1. Abdominal CT scan. Pyloric stenosis associated with dilated stomach. 


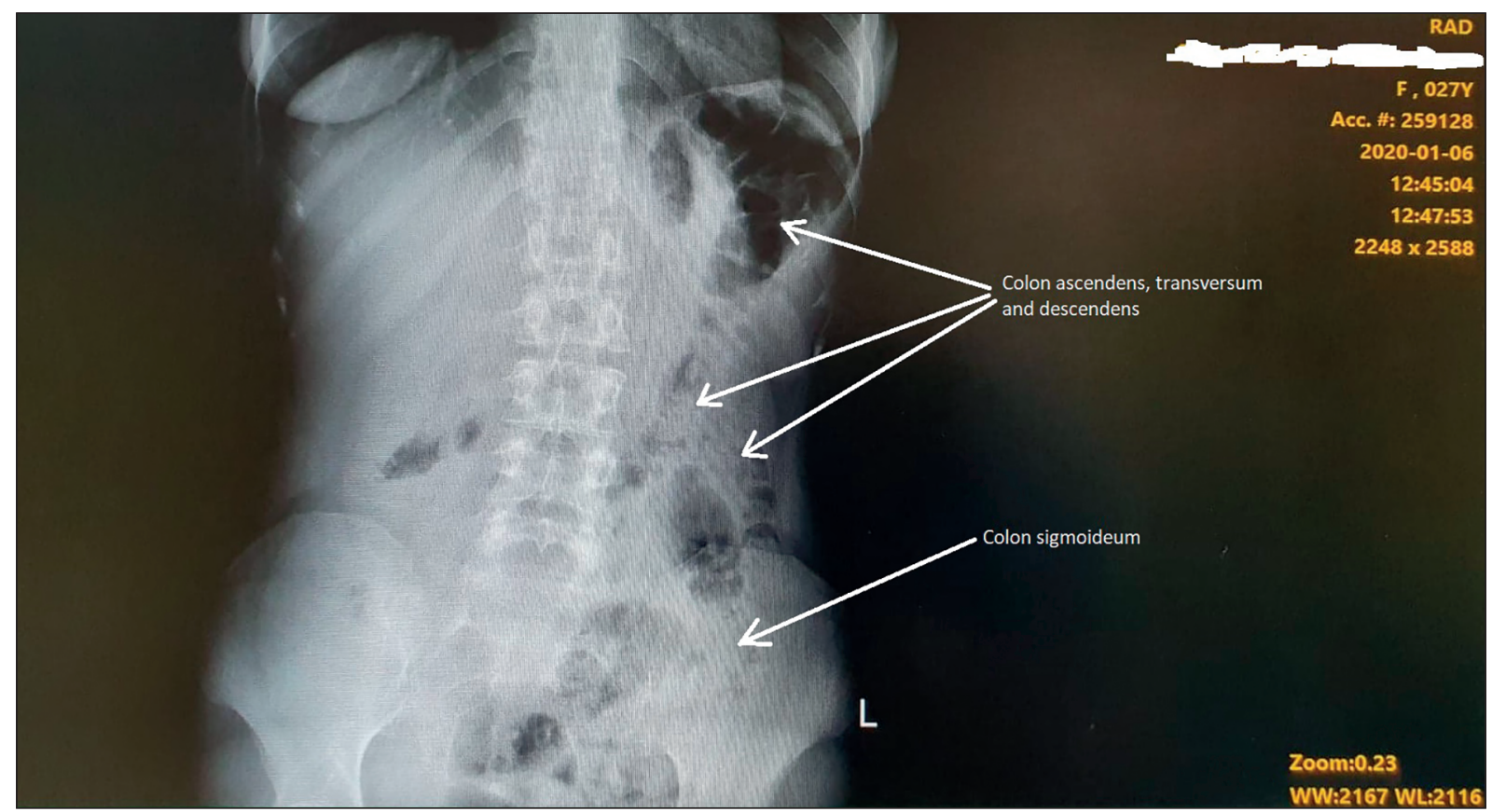

Fig. 2. Abdominal X-ray. Left-sided large intestine.

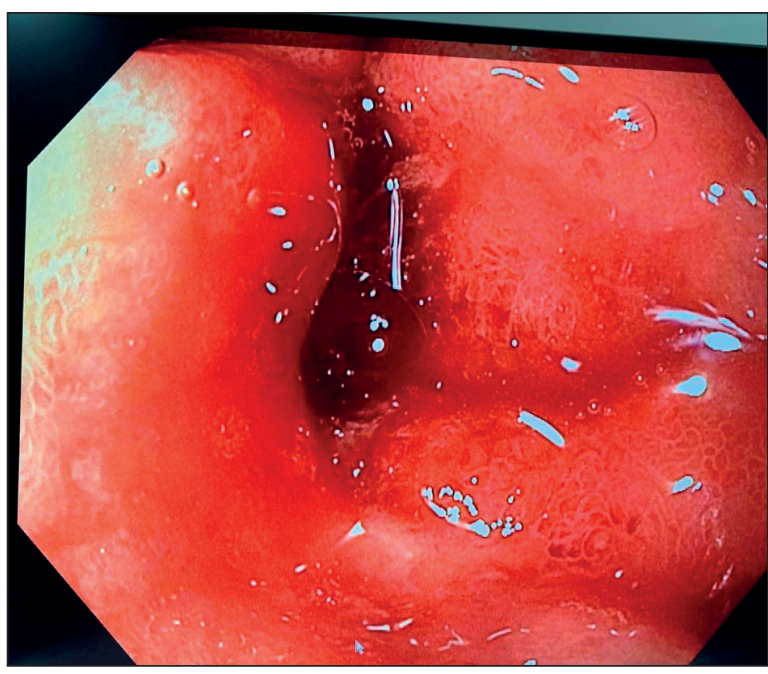

Fig. 3. Gastroscopy. Pyloric stenosis.

decreased appetite, abdominal bloating and $10 \mathrm{~kg}$ weight loss in one month. The gastroscopy showed a duodenal ulcer $($ size $1 / 1 \mathrm{~cm}$ ) on the anterior wall of duodenum 1 , stenosis in the same part of the duodenum and an erythema-exudative pangastritis. The histopathology of the duodenal ulceration has excluded a neoplastic infiltration. Helicobacter pylori test was negative. Conservative treatment was prescribed, with esomeprazole $40 \mathrm{mg}$ and itopride hydrochloride $50 \mathrm{mg}$ three times per day. Hygienic-dietetic regimen has been recommended.

The patient was followed up by a gastroenterologist. Five months later, there was no improvement in the symptoms. The patient was referred to a surgical examination and a computed tomography (CT) imaging with intravenous contrast was performed. CT scan has shown a dilated stomach, pyloric stenosis and intestinal malrotation (Fig. 1).

The patient was admitted to the Military Medical Academy, Sofia, Bulgaria, for elective surgery one month later, in January 2020. Abdominal X-ray and gastroscopy were performed, in order to confirm the diagnosis. The X-ray has shown a left-sided large intestine (Fig. 2) and the gastroscopy has shown a dilated stomach due to pyloric stenosis, with inability to pass the gastroscope distally through the obstruction (Fig. 3).

An upper and middle midline laparotomy was performed under general anaesthesia. Intraoperatively, the examination of the abdominal cavity has found (Fig. 4,5):

a) Pyloric stenosis with inflammation and oedema.

b) Duodenal obstruction due to band.

c) Dilated stomach.

d) Intestinal malrotation (type 2A):

- Duodenum - no duodenal rotation, intraperitoneal location.

- Left-sided large intestine.

- Ladd's band.

The surgical technique consisted in a division of the Ladd's band and Jaboulay pyloroplasty with truncal vagotomy (Fig. 6).

The postoperative evolution was good, without any complications. The normal passage through the gastrointestinal tract was restored. The patient was 


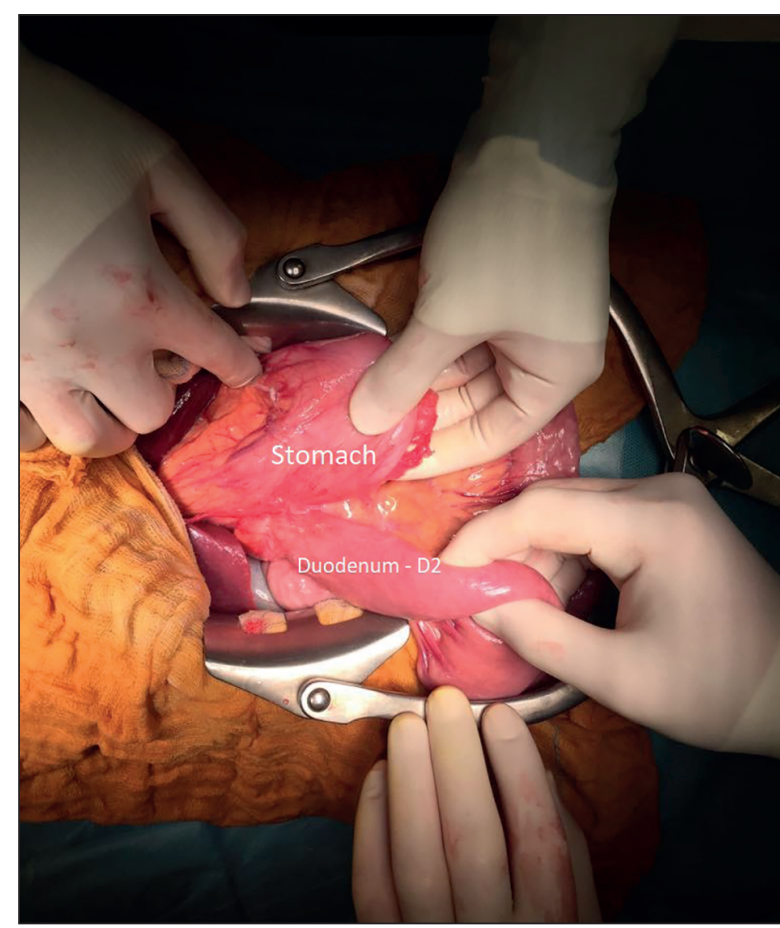

Fig. 4. Intraoperative photo of the intraperitoneal location of duodenum.

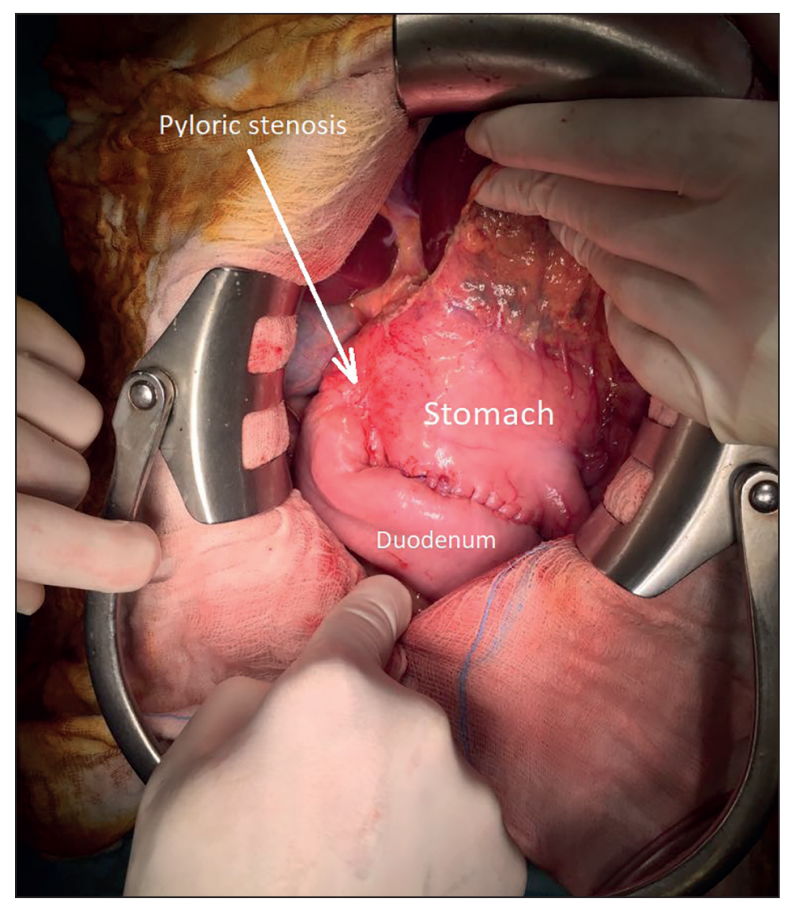

Fig. 6. Intraoperative photo of the Jaboulay pyloroplasty (side-to-side gastroduodenostomy).

discharged in the $7^{\text {th }}$ postoperatory day. The follow-up examination obtained one month after the hospital discharge showed increased quality of life, lack of upper gastrointestinal symptoms and a weight gain of $5 \mathrm{Kg}$.

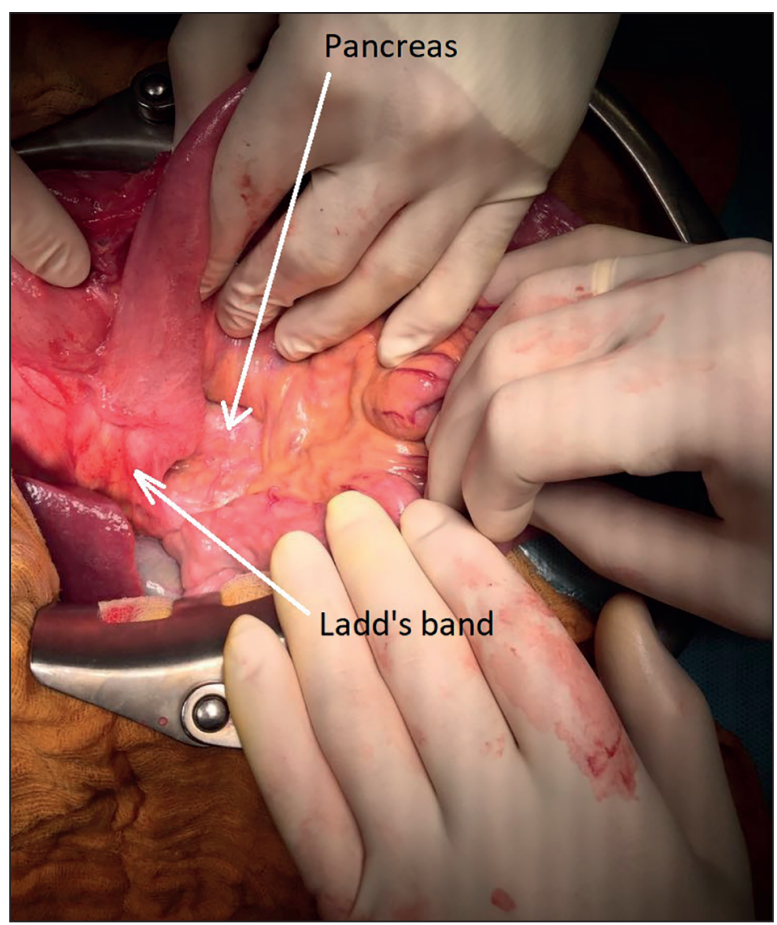

Fig. 5. Intraoperative photo of the intraperitoneal location of the duodenum and the Ladd's band.

\section{Discussion}

Intestinal malrotation is a rare congenital disease $(0.2 \%$ of the new-born children) and it appears as a consequence of incomplete gut rotation and fixation. It was first described in animals by Aristotle and in humans by Fabricii ${ }^{8}$. Intestinal rotation primarily involves the midgut. The rotation of intestinal development has been divided into 3 stages. Stage I occurs in week 5 to 10 . It includes extrusion of the midgut into the extra-embryonic cavity, a $90^{\circ}$ anti-clockwise rotation, and return of the midgut into the foetal abdomen. Stage II occurs in week 11 and involves further anti-clockwise rotation within the abdominal cavity, completing a $270^{\circ}$ rotation. This rotation brings the duodenal "C" loop behind the superior mesenteric artery with the ascending colon to the right, the transverse colon above, and descending colon to the left. Stage III involves fusion and anchoring of the mesentery. The caecum descends, and the ascending and descending colon attach to the posterior abdominal wall9. The type of intestinal malrotation depends on the stage at which the embryonic rotation of the bowel has stopped (Table 1). The type of intestinal malrotation in our case is $2 \mathrm{~A}$.

Intestinal malrotations are most frequently diagnosed in infancy, $75-85 \%$ of all cases in the first year of life ${ }^{1}$. Adults with intestinal malrotation could be asymptomatic or symptomatic (acute or chronic type $)^{12}$. The asymptomatic patients could be discovered 
Table 1. Types of intestinal malrotation ${ }^{10,11}$

\begin{tabular}{|c|c|c|}
\hline Type & Defect & Clinical effect \\
\hline I A & No rotation & Volvulus or middle intestine \\
\hline II A & No duodenal rotation; normal colon rotation & Duodenal obstruction due to bands \\
\hline II B & Inverse rotation of duodenum and colon & $\begin{array}{c}\text { Transverse colon obstruction due to duodenal mes- } \\
\text { entery }\end{array}$ \\
\hline II C & Inverse duodenal rotation; normal colon rotation & Right mesenteric sac (obstruction) \\
\hline III A & Inverse duodenal rotation; no colon rotation & Volvulus of middle intestine \\
\hline III B & Incomplete fixation of the hepatic angle of colon & Obstruction due to Ladd bands \\
\hline III C & Incomplete fixation of the cecum and its mesentery & $\begin{array}{l}\text { Volvulus of the cecum; invagination (Waugh's syn- } \\
\text { drome) }\end{array}$ \\
\hline III D & Internal hernias & Para-duodenal hernia \\
\hline
\end{tabular}

incidentally or the anomaly could be found at autopsy. The symptoms in adults with intestinal malrotation are a consequence of complications due to malposition and lack of fixation of the intestines in the abdominal cavity $^{13}$. The symptomatic pattern of intestinal malrotation could be acute or chronic type. The acute type is the result of volvulus formation or intestinal ischemia, while the chronic type - of a partial obstruction of the intestinal tract. The most frequent symptomatic pattern in adults is the chronic one ${ }^{9}$. All these lead to a difficult diagnosis, which is frequently made in the operation theatre. The gold standard for the diagnosis of intestinal malrotation in adults is abdominal CT imaging with oral or intravenous contrast ${ }^{14,15}$.

AHPS is also a rare disease and presents in adult life as pyloric obstruction, without a history of vomiting in infancy or other gastrointestinal symptoms. The main symptom is upper abdominal distention and discomfort that are relieved by vomiting and accompanied by weight loss. Additional symptoms could be present, such as anorexia and early satiety. The duration of symptoms can range from 5 weeks to 15 years. Diagnosis is based upon history, clinical and radiological findings, and endoscopic appearance $e^{6,7,16}$.

There are 3 types of AHPS $^{6,7}$ :

a) Idiopathic - with no associated lesion in the gastrointestinal tract.

b) Concomitant - occurring in association with a primary lesion in the gastrointestinal tract, such as hiatus hernia, duodenal ulceration, gastric ulceration, inflammatory disease.

c) The late stage of infantile hypertrophic pyloric stenosis.

In this case, the AHPS is concomitant, occurring in association with intestinal malrotation type $2 \mathrm{~A}$ and duodenal ulcer. A review of the literature has shown a similar combination of anomalies only in children. In 1991, Croitoru et al described three cases of intestinal malrotation associated with pyloric stenosis $^{17}$. In 2008, Bhalla et al have incidentally found a similar case ${ }^{18}$. In 2019, Abo Elyazeed et al described a clinical case of intestinal malrotation with a complete Ladd's band associated idiopathic HPS and the accompanied surgical treatment ${ }^{19}$.

The main point of discussion in this associated pathology is the surgical approach, which should be a combination of techniques for treating both diseases. Surgical management of intestinal malrotation at any age is by Ladd's procedure, that consists in the following steps ${ }^{12,14,20}$ :

Division of Ladd's band lying over the duodenum to the caecum.

a) Widening of the narrowed root of the mesentery.

b) Counter-clockwise distortion of the midgut volvulus, if present, and inspecting the bowel to observe if bowel resection is required.

c) Appendectomy, if required.

d) Placing the small bowel to the right and fixing the colon to the left.

On the other hand, the surgical management of HPS is different in children and in adults. The diagnosis in children is made a few days after birth and the classical surgical approach is Ramstedt's pyloromyotomy. Adults with HPS undergo surgical treatment only if they have clinically manifest disease. There are various surgical techniques for AHPS, that could be divided into 3 groups $^{6}$ :

Pyloromyotomy.

a) Pyloroplasty.

b) Pyloric resection with gastroduodeno-, gastroenterostomy or subtotal gastrectomy.

The Fredet-Ramstedt's pyloromyotomy is a less preferred technique, due to its complications, such as mucosal rupture and late duodenal diverticulum formation. The Finney and Heineke-Mikulicz pyloroplasty have good outcomes, but they have some limitations, such as the difficulty in closing the hypertrophic pylorus, and the need to rule out malignancy and peptic ulcer disease. The Jaboulay pyloroplasty is a side-to-side gastroduodenostomy between 
the anterior surface of the stomach and duodenum, without incision of the hypertrophic pylorus. In our case, this technique was considered appropriate due to patient's young age and the existing duodenal mobility, which does not require the Kocher's maneuvers. The pyloric resection with gastroduodenostomy is another option for surgical treatment, but because of the associated possibility of cancer formation at the site of anastomosis $15-20$ years after surgery, it is not a method of choice for young and middle-aged $\operatorname{adults}^{21,22}$.

\section{Conclusions}

Intestinal malrotation associated with AHPS is an extremely rare condition. The combined surgical approach of division of Ladd's band and Jaboulay pyloroplasty in this case appeared to have a good postoperative outcome.

\section{Author Contributions:}

V.I., T.L., I.P., N.V. were responsible for the diagnostic procedures, clinical diagnosis and treatment decisions. I.V. performed the surgery. I.V., V.D. wrote the manuscript. All authors have read and agreed to the published version of the manuscript.

\section{Compliance with Ethics Requirements:}

„The authors declare no conflict of interest regarding this article"

"The authors declare that all the procedures and experiments of this study respect the ethical standards in the Helsinki Declaration of 1975, as revised in 2008(5), as well as the national law. Informed consent was obtained from the patient included in the study"

"No funding for this study"

\section{Acknowledgements:}

None

\section{References}

1. Sipahi M, Caglayan K, Arslan E, Erkoc MF, Aytekin FO. Intestinal malrotation: a rare cause of small intestinal obstruction. Case Rep Surg. 2014;2014:1-4.

2. McVay MR, Kokoska ER, Jackson RJ, Smith SD. The changing spectrum of intestinal malrotation: diagnosis and management. Am J Surg. 2007;194(6):712-9.

3. Wang CA, Welch CE. Anomalies of intestinal rotation in adolescents and adults. Surgery [Internet]. 1963;54:839_ 855. Available from: http://europepmc.org/abstract/ MED/14087118
4. Von Flüe M, Herzog U, Ackermann C, Tondelli P, Harder F. Acute and chronic presentation of intestinal nonrotation in adults. Dis Colon Rectum. 1994;37(2):192-8.

5. Fu T, Tong WD, He YJ, Wen YY, Luo DL, Liu BH. Surgical management of intestinal malrotation in adults. World $J$ Surg. 2007;31(9):1797-803.

6. Christiansen K, Mawr B, Gran A. Hypertrophic pyloric stenosis in the adult. Arch Surg. 1962;85(2):207.

7. Du Plessis DJ. Primary hypertrophic pyloric stenosis in the adult. Br J Surg. 1966;53(6):485-92.

8. Blegen HM. Surgery in situs inversus. Ann Surg. 1949;129(2): 244-59.

9. Mallick IH, Iqbal R, Davies JB. Situs inversus abdominus and malrotation in an adult with Ladd's band formation leading to intestinal ischaemia. World J Gastroenterol [Internet]. 2006;12(25):4093-4095. Available from: https:// europepmc.org/articles/PMC4087730

10. Stringer DA, Babyn PS. Pediatric Gastrointestinal Imaging and Intervention. 2nd ed. 2000, p. 311-32.

11. Ballesteros Gómiz E, Torremadé Ayats A, Durán Feliubadaló C, Martín Martínez C, Caro Tarragó A. Intestinal malrotation - volvulus: Imaging findings. Radiol (English Ed [Internet]. 2015;57(1):9-21. Available from: http://dx.doi. org/10.1016/j.rxeng.2014.07.002

12. Emanuwa OF, Ayantunde AA, Davies TW. Midgut malrotation first presenting as acute bowel obstruction in adulthood: A case report and literature review. World J Emerg Surg. 2011;6(1):2-7.

13. Socea B, Nica AA, Bratu $O$, et al. Incidental finding of a sigmoid intussusception associated with rectal prolapse - a case report. Arch Balk Med Union 2018;53(1):143-146

14. Herle $P$, Halder T. Intestinal malrotation in an adult patient with other congenital malformations: A case report. Int J Surg Case Rep [Internet]. 2018;51:364-7. Available from: https://doi.org/10.1016/j.ijscr.2018.09.010

15. Nehra D, Goldstein AM. Intestinal malrotation: Varied clinical presentation from infancy through adulthood. Surgery [Internet]. 2011;149(3):386-93. Available from: http:// dx.doi.org/10.1016/j.surg.2010.07.004

16. Danikas D, Geis WP, Ginalis EM, Gorcey SA, Stratoulias C. Laparoscopic pyloroplasty in idiopathic hypertrophic pyloric stenosis in an adult. JSLS. 2000;4(2):173-5.

17. Croitoru D, Neilson I, Guttman FM. Pyloric stenosis associated with malrotation. J Pediatr Surg. 1991;26(11):1276-8.

18. Bhalla VK, Harper JG, Hatley RM, Howell CG, Pipkin WL. Laparoscopic treatment of simultaneously occurring pyloric stenosis and malrotation. J Laparoendosc Adv Surg Tech. 2008;18(4):641-3.

19. Abo Elyazeed AM, Shalaby MM, Awad MM, Effat AM, Abdella AE, Shehata SM. Idiopathic hypertrophic pyloric stenosis with complete Ladd's band: a rare association. Eur J Pediatr Surg Reports. 2019;07(01):e66-8.

20. Zengin A, Uçar BI, Düzgün ȘA, et al. Adult midgut malrotation presented with acute bowel obstruction and ischemia. Int J Surg Case Rep. 2016;22:5-7.

21. Ohashi M, Katai H, Fukagawa T, Gotoda T, Sano T, Sasako $\mathrm{M}$. Cancer of the gastric stump following distal gastrectomy for cancer. Br J Surg. 2007;94(1):92-5.

22. Takeno S, Noguchi T, Kimura Y, Fujiwara S, Kubo N, Kawahara K. Early and late gastric cancer arising in the remnant stomach after distal gastrectomy. Eur J Surg Oncol. 2006;32(10):1191-4. 